\title{
“428 Millions of Quadrilles for 5s. 6d.": John Clinton's Combinatorial Music Machine
}

\author{
NIKITA BRAGUINSKI
}

Published in London around 1865, the Quadrille Melodist was an elaborate paper-based system for the generation of piano pieces. Its author John Clinton, a "professor in the Royal Academy of Music," was and still is almost exclusively known for his role in the history of the flute. ${ }^{1}$ Yet his Melodist, essentially a predigital musicgenerating machine, shows that Clinton's inventiveness did not stop at the construction of novel flute mechanisms. Drawing on the history of rule-based musical systems, Clinton's method constituted an attempt at mechanizing the compositional process using the theories and technologies of the Victorian era. In hindsight,

\footnotetext{
${ }^{1}$ See, for example, Niall O'Loughlin and Robert Bigio's entry on John Clinton in Grove Music Online, which describes him as a "flutist, composer, flute designer, and manufacturer" who "became professor of flute at the Royal Academy of Music in the 1840s" and in 1848 "registered the first of his four patents for flutes." Born in 1809, Clinton died in London in 1864: https://doi.org/10.1093/ gmo/9781561592630.article.L2290772.
}

it can be read as a statement against the idealist impulse of the early nineteenth century in which-adopting Kant's famous formulation"the genius does not know himself how he has come by his ideas; and he has not the power to devise the like at pleasure or in accordance with a plan, and to communicate it to others in precepts that will enable them to produce similar products. $^{\prime 2}$ As we will see, Clinton's method was planned, rule-based and was communicated in terms that would produce similar results. Whereas music-playing automata ranging from simple music boxes to fully developed sculptural imitations of human players were widely known and acknowledged during the seventeenth and eighteenth centuries, creative processes were much less susceptible to mechanical imitation. ${ }^{3}$

\footnotetext{
${ }^{2}$ Immanuel Kant, Critique of Judgment [1791], trans. J. H. Bernard (New York: Haffner, 1951), 151.

${ }^{3}$ An overview of musical automata and combinatorial music of the seventeenth and the eighteenth centuries is available
} 
As a professional musician, Clinton was able to apply musical methods such as theories of harmony, form, and voice leading to his system. By doing so, he transformed his personal knowledge into a technologically embodied knowledge independent from his own ability to carry out the needed work. However, his use of mathematics fell short of nineteenth-century understanding of combinatorics and, in fact, even earlier examples of such methods. At the same time, the Quadrille Melodist foreshadowed later developments in algorithmic music that did not gain traction until the advent of computer technology after the Second World War. Despite its ease of use and well-conceived design, the commercial success of the Quadrille Melodist seems to have been fairly limited; only a few copies of it have survived in libraries worldwide. A complete copy of the system, held at the British Library, however, makes possible an analysis of both its musical structure (harmony, melody, rhythm, form) and its combinatorial properties. ${ }^{4}$

In this article, I analyze the Quadrille Melodist against the background of the history of combinatorial music. I contrast its unique features with other predigital, as well as later digital music systems and discuss its design with respect to the phenomenon of predictability in dance music of the period. Additionally, I discuss reasons for the circumstance that the historically advertised number of possible quadrilles, 428 million, is much smaller than the real number of combinations. ${ }^{5}$

\section{A Kaleidoscope of Quadrilles}

The Quadrille Melodist consists of a box with cards containing short snippets of piano music.

in Sebastian Klotz, Kombinatorik und die Verbindungskünste der Zeichen in der Musik zwischen 1630 und 1780 (Berlin: Akademie Verlag, 2006).

${ }^{4}$ John Clinton, The Quadrille Melodist, Consisting of an Almost Endless Variety of New Quadrilles, Composed and Invented for the Pianoforte, by J. Clinton, Professor in the Royal Academy of Music, Op. 83 (London: E. Butler \& Co, n.d.). The British Library call number is: Music Collections M.1. / BLL01004272934.

${ }^{5}$ In this article, I use the term "combination" rather than a different term from the mathematical discourse on combinatorics, "permutation," because of its connection to the historical musical-mathematical term ars combinatoria, which was the common descriptor discussed here for the methods at the time of their creation.
These snippets can be shuffled and recombined on a special tray with slots (see plate 1). To preserve the musical logic, each card has a predefined position within the musical piece. Thus, the underlying harmony and even the voice leading are preserved while the generated music changes with each new combination of the cards. Two sets of cards are provided, each corresponding to one dance from the traditional set of originally five quadrille dances. It cannot be said with certainty whether Clinton composed the music or, rather, wrote variations on two pieces from some existing quadrille. In any case, a considerable amount of work was needed to create the two sets of musical snippets that make up his system. Cards forming one dance all share a common musical logic. In turn, this also means that cards belonging to different dances cannot be combined with each other owing to the metrical and tonal differences between the pieces.

Although the Quadrille Melodist was produced using the four-hundred-year-old technology of music printing, as a medium it differs from traditional printed sheet music. Because its musical material is presented as a set of stacks of cards, with each stack providing multiple variations of the corresponding bar, the music can be changed. That is, it is an interactive format. This added possibility of carrying out operations with the cards (such as sorting, shuffling, or choosing) shifts the meaning of what the Melodist is. Instead of offering a static representation of existing music, Clinton's system becomes a tool for the mechanical production of new pieces. With its help, a person capable of reading musical notation and playing the piano can produce new material that-it would seem-is practically indistinguishable from what we might call the uninspired, but knowledgeable work of a routine composer, not dissimilar to what Hanslick once termed musical "Fabriksarbeit." ${ }^{16}$

From a practical point of view, the Quadrille Melodist is eminently suitable for application. Tapping into the tradition of turning the pages of a piano piece during play, Clinton gives the player the opportunity easily to reorder one or

\footnotetext{
${ }^{6}$ Eduard Hanslick, Musikalisches und Litterarisches: Kritiken und Schilderungen, 2nd edn. (Berlin: Allgemeiner Verein für Deutsche Litteratur, 1889), 54.
} 


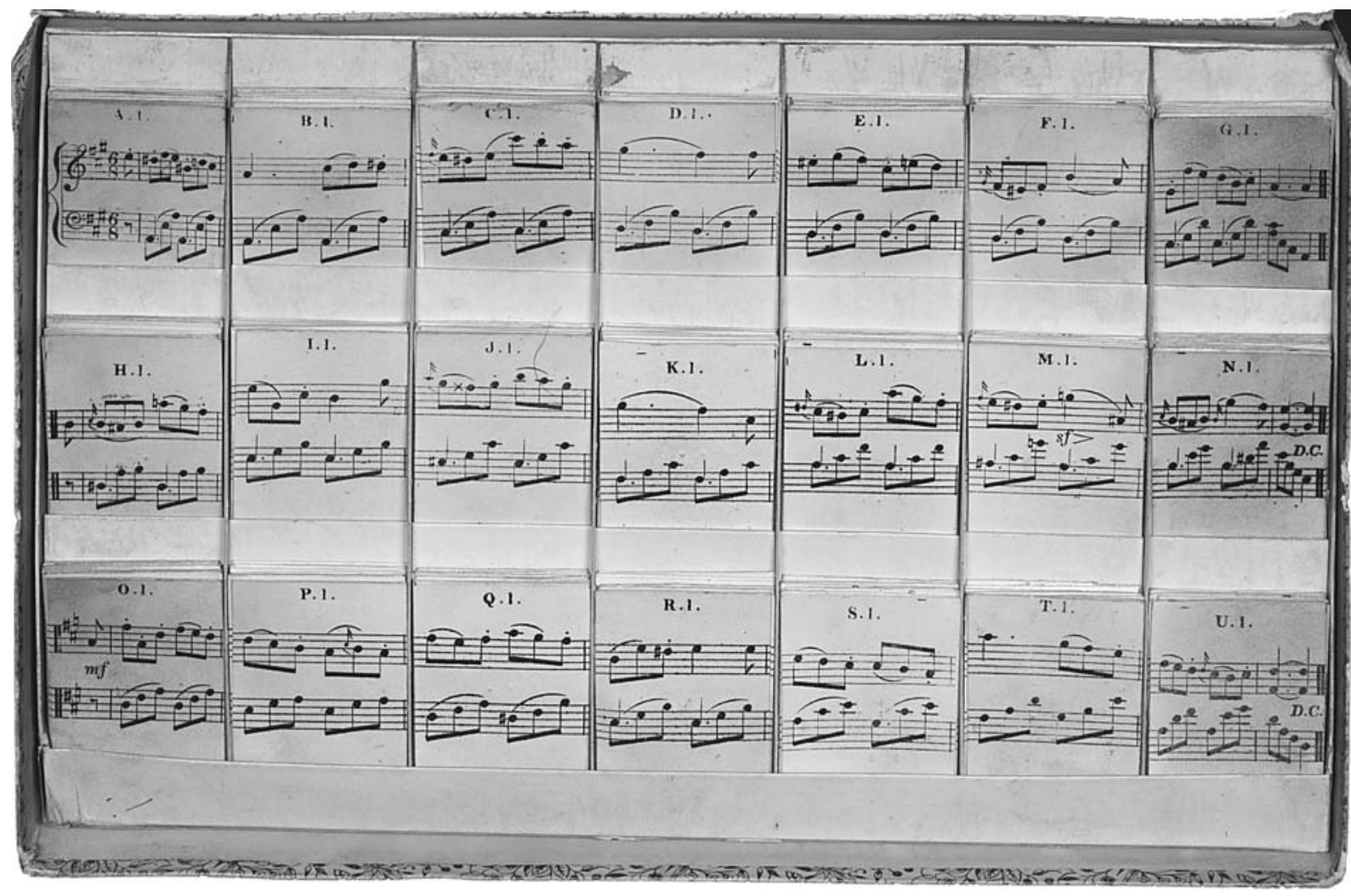

Plate 1: The tray of the Quadrille Melodist holding the cards labeled A1-U1.

(C) British Library Board (Music Collections M.1.).

several stacks of cards between performances or even between single repetitions of the "same" piece. Thus, music with differing degrees of unpredictability between individual playing sessions can be produced. For the player, it is possible to play the quadrille dance in the same combination, with only slight changes, or with a fully new arrangement of cards.

To represent quadrille dances in ternary as well as in quadruple meters, Clinton chose ${ }_{8}^{6}$ and ${ }_{4}^{2}$ as time signatures for the two pieces of his system. In Clinton's "Directions for Use" - a two-page preface explaining how the apparatus works-the pieces are called $L e$ Pantalon (single-lettered cards, 6) and L'Été (double-lettered cards, ${ }_{4}^{2}$ ), corresponding to titles of well-known dances within the quadrille genre. Each piece in the Quadrille Melodist consists of three periods of eight measures. This musical material is mapped onto an arrangement of $3 \times 7$ cards. While such a reduction of the number of cards might seem counterintuitive at first, Clinton's system in fact represents a musically meaningful variation of the underlying mathematical grid. Instead of rigidly allocating one measure to each card, Clinton has combined elements that form a motive or a part of a phrase, such as the upbeat note along with its subsequent measure, or the two measures that form a closing figure at the end of the eight-measure period. They are thus also commentaries on the constituent elements of style and the expectation of the genre. At the same time, Clinton's extensive use of da capo repetitions helps keep the number of measures to a minimum, which is crucial in this case, as multiple variations of each measure need to be provided by the composer and publisher.

Overall, the Quadrille Melodist box contains 462 cards, consisting of two pieces each of which occupies 21 slots in the tray, with 11 cards per slot. The labels printed on the cards identify 
them as belonging to one of the pieces (singlelettered vs. double-lettered), as corresponding to one of the slots (letters A to U and AA to UU) and as having a place in the stack of cards in each slot (numbers 1 to 11). Thus, the card A1 is the first card in the stack occupying the first slot of the first piece.

In traditional terms, each set of cards holding the same number (for example, from A1 to U1) could be seen as representing a single variation of the piece. Technically, it is quite possible that the music was first printed on large sheets of paper each corresponding to such a complete variation and that this was only later cut into individual cards; certainly, it seems likely that the music was composed in this way. However, as the cards can be reshuffled freely within their slots, they form a grid-like map of musical material that can be traversed in multiple ways. Thus, by constituting a collection of interchangeable, separable units instead of a predefined piece, the Quadrille Melodist evades the traditional notion of a set of variations. Instead, it is closer to melodic improvisation, where the invention of new lines on the basis of a fixed repertoire of motives alters the surface of music, but not its harmonic structure.

As a system, the Melodist offers a balance between predictability and unpredictability that would seem well suited for ballroom dance music. While the form is maintained through the application of the eight-measure scheme, a certain degree of melodic and harmonic change can easily be introduced by the player if he or she replaces some of the cards. The homogeneity of Clinton's music in the Quadrille Melodist thus turns out to be an indispensable prerequisite for the functioning of the system, as it ensures stylistic stability across individual renditions, even with randomly shuffled cards within each slot.

A comparison of two different arrangements of cards, given in exs. 1-2, shows that the replacement of individual elements of Clinton's system does not threaten the consistency of its harmonic progressions and voice leading. Take, for example, the first measure: substituting the card A1 for A2 does not change the underlying harmony at all, and even retains the last note $\left(\mathrm{c}_{\#}\right)$ and the falling melodic line that connects to the first note of the next card. At the same time the articulation of the melody is varied by changing the grouping of slurred and staccato notes, often by a process of reversal.

Perhaps with an eye to marketability, the generated music is simple enough to be suitable for amateur pianists. With a mostly two-voice texture in which the left hand is restricted to ostinato arpeggios, the level of difficulty has been carefully calibrated to enable the easy accompaniment of dance at home or at a social event. ${ }^{7}$ As a professor at the Royal Academy of Music, Clinton, perhaps unsurprisingly, also presented his work with a modicum of musical-didactical reflection. His "directions for use" notes that measures too difficult for the player can be replaced, and that the system can also be used to train musicians in the reading of notation. Another source, the catalogue of Clinton's flute works (which also includes other types of music) even proposes the use of the Melodist as tool for exercises in composition. ${ }^{8}$ Given Clinton's primary field, it is notable that a flautist could easily play from the cards, since the range of the melody falls conspicuously within that of the flute, and the occasional second voice could be omitted.

The accompanying "directions for use" document states that "by calculation it is ascertained that, from the single-lettered Cards alone, 214 millions of Quadrilles or Melodies may be obtained." Correspondingly, advertising materials of the time use the number of 428 million, which seems logical given that there are two sets of cards (see plate 2). However, it can be easily shown that this number is incorrect. Each stack contains eleven cards. Thus, there are eleven possibilities for selecting the first card, and for each of them there are eleven possibilities to choose the

\footnotetext{
${ }^{7}$ Despite the homogeneity of the music in the Quadrille Melodist, which derives from the building-block approach that is at the heart of Clinton's method, the resulting melodies do hold in themselves a certain aesthetic quality with a lot of chromatic embellishment, grace notes, dynamic change, and an occasional harmonic surprise.

8 "An amateur, possessed of taste, or a natural gift for melody, might compose one bar similar in style to one of the Cards, the correctness or incorrectness of which will be proved by the Cards which immediately precede and follow it: $t w o$ measures might then be composed, and so on gradually, until a whole part be completed." John Clinton, Clinton's Flute Works: A Select Catalogue of Music, Consisting Exclusively of J. Clinton's Compositions and Arrangements for the Flute (London: Joseph Mallett, n.d.), 17.
} 
19 TH CENTURY MUSIC
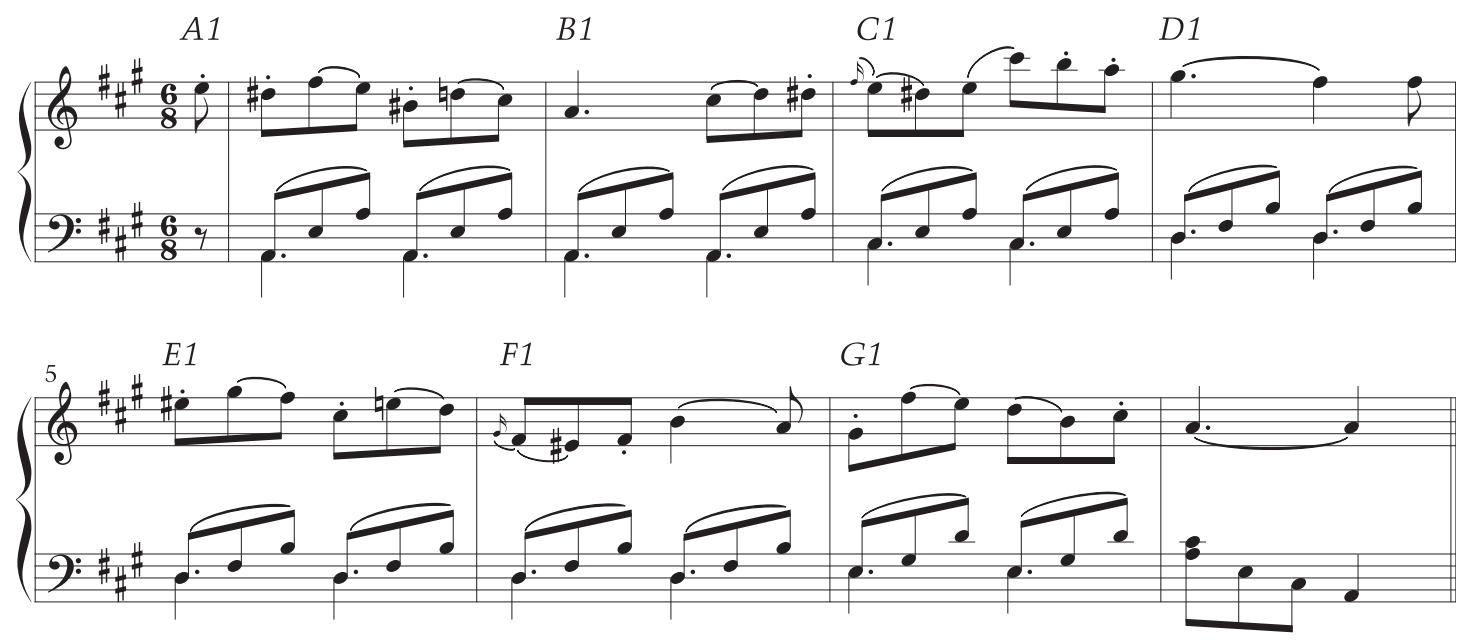

Example 1: The first eight-measure period of the first piece, assembled from the cards titled A1 to G1 (seen in plate 1).
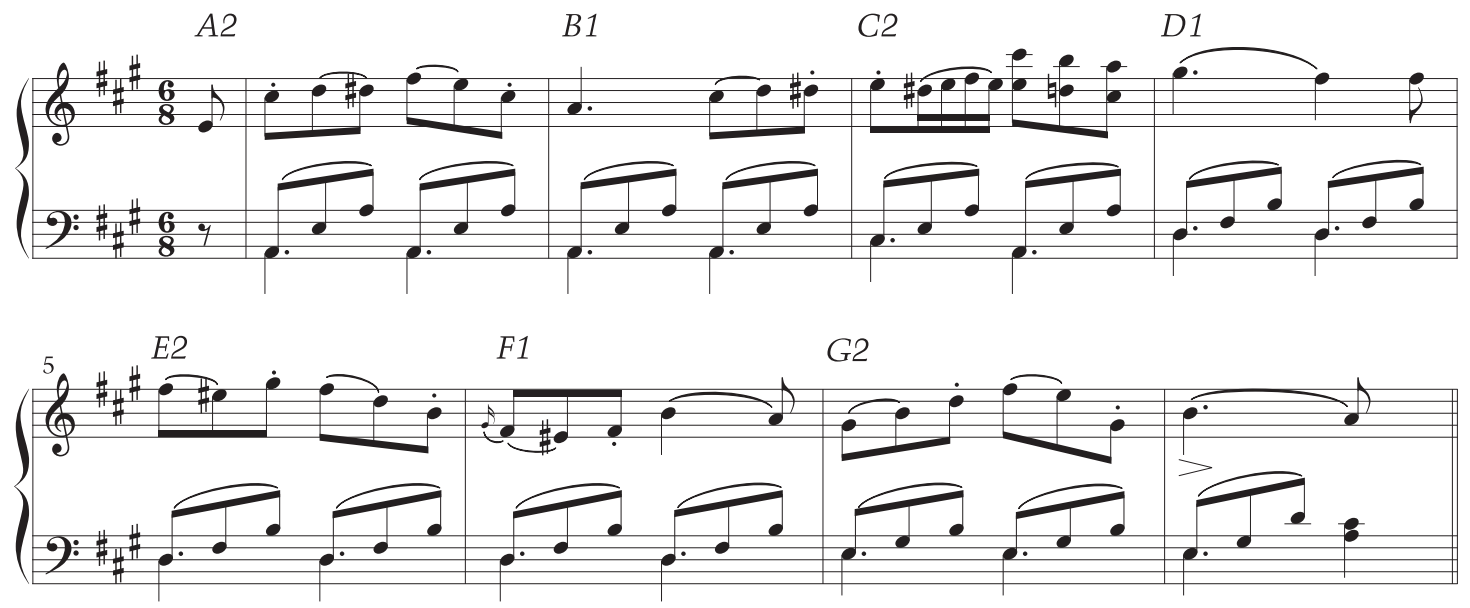

Example 2: Here, all odd-numbered cards from example 1 were replaced by the next card in the stack, leading to the following arrangement: A2, B1, C2, D1, E2, F1, G2.

second card, etc. With only two stacks there would have been eleven to the power of two combinations. With twenty-one stacks, there are eleven to the power of twenty-one combenations for each piece. This means that the number used by Clinton is, ironically, many orders of magnitude smaller than the correct result which is $7,400,249,944,258,160,101,211$ or just over 7.4 sextillion combinations. This circumstance is even more stunning because in the nineteenth century it would have been tival for a specialist to calculate the correct mumber, and Clinton (or his publisher) would have had ready access to mathematicians in London and Cambridge. ${ }^{9}$ Also, musical-mathematical texts containing numerous examples of combinatorial calculations of similar or higher

${ }^{9}$ At the same time, with eight stacks, a number of combinetons can be achieved that comes remarkably close to the one mentioned in the Quadrille Melodist: 214,358,881. Since the individual musical phrases in the Melodist have the length of eight measures, this was probably the source of the wrong calculation. Note that this is also the number of possible combinations for one table of the Musikalisches Würfelspiel (discussed below), and therefore the number could also have been copied from an analysis of that system.

90 
complexity had been circulating since at least the seventeenth century, ranging from Marin Mersenne's publications to works by Kircher, Leibniz, and Euler written over the course of the seventeenth and eighteenth centuries. ${ }^{10}$ The ease with which the wrong number was used in advertisement clearly indicates that the system was marketed to an amateur audience that lacked professional skills in both music and mathematics, rather than to a scientific community interested in developments in musical combinatorics or in philosophies of sounding number.

\section{Musical Machines}

When compared to other music-generating systems of the nineteenth century, the Quadrille Melodist stands out because of its effectiveness and convenience. One of the most prominent examples, the Musikalisches Würfelspielattributed to Mozart-is similar in its use of single measures as individual units for random recombination, but differs from the Melodist because of the difficult process that precedes the creation of the piece. ${ }^{11}$ In the Musikalisches Würfelspiel, a random number first needs to be determined by throwing a pair of dice, then the user needs to consult a table containing measure numbers, and then the corresponding measure needs to be copied before the procedure can be repeated to determine the next measure. By contrast, a pianist capable of sight-reading can use the Quadrille Melodist to generate music in real time by gradually replacing the cards in the tray. ${ }^{12}$

\footnotetext{
${ }^{10}$ See Eberhard Knobloch, "The Sounding Algebra: Relations between Combinatorics and Music from Mersenne to Euler," in Mathematics and Music: A Diderot Mathematical Forum, ed. Gerard Assayag, Hans Georg Feichtinger, and Jose Francisco Rodrigues (Berlin: Springer, 2002), 27-48. Further mathematical-historical context may be found in Combinatorics: Ancient and Modern, ed. Robin Wilson and John J. Watkins (Oxford: Oxford University Press, 2013).

${ }^{11}$ W. A. Mozart [attributed], Instruction to compose without the least knowledge of Music so much German Walzer or Schleifer as one pleases, by throwing a certain Number with two Dice (Bonn: N. Simrock, n.d.) http://imslp.org/wiki/ Musikalisches_W\%C3\%BCrfelspiel,_K.516f_\%28Mozart, Wolfgang_Amadeus\% 29.

${ }^{12}$ At the same time, the difficult procedure prescribed by the rules of the Musikalisches Würfelspiel may also be seen as a game-like element that can be enjoyed by the user in the same way as a Patience or a Solitaire playing session. The
}

The construction used by Clinton, although similar in some respects to the Musikalisches Würfelspiel, differs from it in being a machine, rather than merely a set of data, an algorithm or an instruction. The time component is crucial in this case. In a temporal art form such as music the speed of operation determines whether the tool can be used live, or whether it presupposes a period of preparation. Thus, while the mathematical structure of the Würfelspiel resembles the core elements of the Melodist, its status as a tool is different. Since the Melodist mechanizes the logical process of keeping the needed level or musical order (by offering the tray system), it resembles more the mechanical calculation machines of the nineteenth century such as Charles Babbage's Difference Engine than a traditional score. ${ }^{13}$ The most important parallel between the Difference Engine and the Melodist is here the underlying conviction that a complex mental process can be subdivided into simple, mechanisable steps. Thus, the Melodist consists of a set of discrete but interrelated functions such as "prepare a set of interchangeable cards" and "shuffle the cards." Some of these functions could be carried out by Clinton in advance while others would have to be carried out during each new performance.

At the same time, Clinton's system also exhibits visible parallels to the approach used in the Würfelspiel. A combination of letters and numbers is used in both systems to label and locate the musical snippets with the goal of creating dance music. Also, the otherwise inexplicable number of eleven cards in each

use of dice for musical games did not start with the Musikalisches Würfelspiel. For a list of musical systems of the eighteenth and nineteenth centuries, including an early dicebased method, see Philippe John van Tiggelen, Componium: The Mechanical Musical Improvisor (Louvain-la-Neuve: Institut supérieur d'archéologie et d'histoire de l'art, 1987), $327-38$.

${ }^{13}$ For a discussion of connections between Babbage's calculators and musical machines, see Rebecca Wolf, "Musik und Mechanik bei Johann Nepomuk Mälzel," Archiv für Musikwissenschaft 66, no. 2 (2009): 116-17; and David Trippett, "Exercising Musical Minds: Phrenology and Music Pedagogy in London circa 1830" this journal 39 (2015): 122, https://doi. org/10.1525/ncm.2015.39.2.99. Being a much simpler mechanism, the Quadrille Melodist does not reach the complexity of Babbage's proposed calculators. However, this simplicity also made the actual creation and mass-production possible by relying on well-established technologies of the nineteenth century. 
stack of the Melodist tray seems to derive directly from the Würfelspiel: By throwing two dice, eleven different numbers can be obtained (as sums of dots). ${ }^{14}$ Given the popularity of the Würfelspiel, it is quite possible that Clinton was aware of this earlier system and borrowed this aspect from it. Like the Melodist, the Würfelspiel offers eleven variations of each measure. Consequently, this number deeply structures the tables and the amount of musical material provided within both systems.

The Würfelspiel was part of a whole genre of quasi-algorithmic composition systems that emerged at the beginning of the nineteenth century. In 1801 Antonio Calegari's Gioco pitagorico musicale was published in Venice. ${ }^{15}$ Despite Calegari's gradual changes to the Würfelspiel system and its greater musical flexibility, the general approach of his "Pythagorean musical game" is based directly on the Würfelspiel in its reliance on two dice, a similarly designed table and a section of numbered musical material. The anonymously published Melographicon system (undated, ca. 1825) can be seen as a logical intermediate step between the Würfelspiel and the Melodist. ${ }^{16}$ Although the musical material is still presented in it as a numbered collection of measures, dice are not employed, and the user is encouraged to choose measures intuitively or randomly. Crucially, however, the book instructs the reader that by cutting out the single printed measures and arranging them in stacks according to the letter printed on them, the process of composition can be accelerated. ${ }^{17}$ In other words, the Melographicon presents itself as

\footnotetext{
${ }^{14}$ It also corresponds to the original price of eleven shillings, which was reduced by half by the time the system was being advertised (see the last line in plate 2).

${ }^{15}$ Antonio Calegari, Gioco Pitagorico Musicale col quale potrà Ognuno, anco senza sapere di Musica, formarsi una serie quasi infinita di picciole Ariette, e Duettini per tutti li Caratteri, Rondò, Preghiere, Polacche, Cori ec. (Venezia: Presso Sebastiano Valle, 1801), http://www.internetculturale. it/jmms/iccuviewer/iccu.jsp?id=oai:www.internetculturale. sbn.it/Teca:20:NT0000:IT||ICCU||PUVE||001558.

${ }^{16}$ Anonymous, The Melographicon: A New Musical Work, by Which an Interminable Number of Melodies May Be Produced, and Young People Who Have a Taste for Poetry Enabled to Set Their Verses to Music for the Voice and Piano-Forte, without the Necessity of a Scientific Knowledge of the Art (London: Clementi and Co., n.d.).

${ }^{17}$ Ibid., iv and $\mathrm{x}$-xi.
}

a compositional aid and a malleable medium whose status-book or machine-can be determined by the user. The descriptions accompanying the Quadrille Melodist also seem to derive partially from the explanations given in the Melographicon. For example, the suggestions to replace individual measures that do not fit in, or to write down especially successful combinations can be found both in the Melodist's "directions for use" and in the Melographicon. Both methods are also explicitly targeted toward nonprofessionals, much like the Würfelspiel (an "instruction to compose without knowledge of music") and the Gioco pitagorico musicale.

Like Clinton, who compares his musical system to a kaleidoscope, the anonymous author of the Melographicon uses a visual comparison to explain the essence of the system. ${ }^{18}$ Clinton's use of the kaleidoscope to explain the essence of his system, however, is not entirely satisfactory. A kaleidoscope is a toy that produces everchanging arrangements of colorful pebbles whose chaotic movements are given a certain degree of order by a set of mirrors that create a symmetric picture. Kaleidoscopes are visually disorientating and thus do not constitute a viable parallel to Clinton's carefully crafted system beyond the obvious comparison that individual elements are being reshuffled in both cases. By contrast, the author of the Melographicon employs a much more direct cue by making a connection between this system and a Myriorama. A Myriorama, as it was popularized by publishers in the early nineteenth century, was a collection of cards with printed views that could be combined in any order to produce a combinatorial picture, usually of a landscape. ${ }^{19}$ There are several connections that can be made between the structure of a Myriorama and the internal logic of the Quadrille Melodist. Beyond the simple fact that both systems include a set of individual cards and are held in boxes (rather

\footnotetext{
${ }^{18} \mathrm{~A}$ kaleidoscope is an optical toy that creates visual effects through a combination of a randomly changing arrangement of small objects and a system of mirrors. It can be seen as an example for the mechanical creation of unpredictability for aesthetical purposes.

${ }^{19}$ For a discussion of Myrioramas and several photographs of combined pictures, see Ralph Hyde, "Myrioramas, Endless Landscapes: The Story of a Craze," Print Quarterly 21, no. 4 (2004): 403-21.
} 
than forming a book), there are also parallels in the layout of individual cards. In order for the Myriorama cards to be compatible with each other, the landscapes that are printed on them need to touch the edges of the card at the same height. Moreover, to offer a logical continuation of a line that begins on one card and ends on another (such as a slope of a mountain), the direction of such lines must be consistent across cards. The same principles also apply to melodic lines printed on individual cards. As exs. 1 and 2 demonstrate, Clinton implicitly followed the lessons that can be learned from using a Myriorama, even without mentioning it directly.

Whereas the Melodist is a piano-orientated system, the Melographicon is geared toward vocal composition and as such also needs to take into account the poetic meter of the lyrics. To facilitate the use of a system that relies on the rhythmic understanding of both music and poetry, the Melographicon includes an explanatory section that gives a short overview of different poetic meters and their appropriate areas of use. Here, the user is advised to choose poetic meters according not only to the musical time signature, but also to the atmosphere of the lyrics. Thus, the iambic foot and the anapest are suggested for "sprightly" verses while the use of the trochee is reserved for "pensive" poetry. ${ }^{20}$ In doing so, the Melographicon follows a line in the development of combinatorial music that goes back to at least the seventeenth century, with Athanasius Kircher's treatise Musurgia Universalis from 1650 as an important cornerstone. ${ }^{21}$ Like the author of the Melographicon more than one and a half centuries after him, Kircher gives concrete guidance as to which

\footnotetext{
${ }^{20}$ Anonymous, The Melographicon, ix.

${ }^{21}$ Athanasius Kircher, Musurgia Universalis Sive Ars Magna Consoni et Dissoni in X. Libros Digesta (Rome: Corbelletti, Grignani, 1650|. A discussion of the musical and mathematical contents of Kircher's book, including an analysis of its controversial reception, is offered in John Zachary McKay, Universal Music-Making: Athanasius Kircher and Musical Thought in the Seventeenth Century ( $\mathrm{PhD}$ diss., Harvard University, 2012), http://nrs.harvard.edu/urn-3:HUL.InstRepos:10382782. Further biographical, historical, and cultural context on Kircher's writing and his use of paper-based devices is offered in Siegfried Zielinski, Deep Time of the Media: Toward an Archaeology of Hearing and Seeing by Technical Means (Cambridge, MA: MIT Press, 2006), 101-57.
}

musical rhythms fit certain poetic meters. ${ }^{22}$ But Kircher also offers instructions for the creation of a musical composition machine whose structure resembles the internal logic of nineteenth-century music systems. After offering numerous examples of musical combinatorics throughout the eighth book of his Musurgia Universalis, Kircher proposes the building of a box with movable slates containing musical tables, called an arca musurgica or, alternatively, arca musarithmica. ${ }^{23}$ By proposing the transfer of the musical material from the static medium of a book into a mechanical device, Kircher thus prepares the ground for the practical use of musical cards and trays in the nineteenth century (though in Clinton's case there is no suggestion that he was a Latinist with access to Kircher's treatise).

While the musical systems discussed above all rely on a human operator who chooses cards or measures and plays them, there was at least one early-nineteenth-century musical machine that functioned autonomously. The Componium, created by Dietrich Nikolaus Winkel in 1821, used a mechanical randomization apparatus that switched unpredictably between snippets of music stored on two barrels. ${ }^{24}$ Originally multiple individual barrels were created, of which seven have survived. ${ }^{25}$ Automata capable of merely playing static musical programmes, such as music boxes, were not a novelty by the time of the Componium, but by automating the process of random choice of the musical material the Componium goes beyond the capabilities of the other systems. As a machine that both generates and plays combinatorial pieces, it already points toward the digital music-producing technologies of the late twentieth century.

At first sight, the Quadrille Melodist's simple mechanics seem to be incommensurable with the complexities of today's electronic, algorithmic, and data-based approaches. The overview of advanced techniques of computer-assisted

\footnotetext{
${ }^{22}$ See McKay, Universal Music-Making, 274-77.

${ }^{23}$ Ibid., 302.

${ }^{24}$ A detailed description of the mechanism, including the randomization part that the author compares to the workings of a roulette wheel, is offered in Tiggelen, Componium: The Mechanical Musical Improvisor, here 315.

${ }^{25}$ Ibid., 324.
} 
algorithmic composition given by Gerhard Nierhaus, for example, makes clear the extent to which modern musical systems rely on the resources of the digital computer. ${ }^{26}$ However, from the point of view of the system's internal structure, the Melodist does share some characteristics with specific digital musical technologies. As mentioned above, the network of the Quadrille Melodist's musical snippets can be traversed in multiple ways, each representing one possible combinatorial piece. This creates a direct parallel to later digital technologies that assemble music from predetermined pieces. Computer games belonging to the "Adventure" genre, for example, connect virtual "rooms," and also their accompanying background music, into a net of nodes. This network can be traversed by the player in many different ways, thus constructing a combinatorial meta-structure out of individual pieces of background music. ${ }^{27}$

The structural parallels between the nineteenth-century music machines under discussion and those of today, however, are not their only, and possibly not even their most salient shared characteristic. The discourse that influenced the public's understanding of combinatorial music continues to revolve around the tension between the ideas of creativity and mechanicity. ${ }^{28}$ The act of composing art has been linked to notions of divine inspiration at least since Plato's Ion, while during the Romantic period notions of self-expression and ingenuity were inflected by writings from the Jena Romantics and criticism

\footnotetext{
${ }^{26}$ Gerhard Nierhaus, Algorithmic Composition: Paradigms of Automated Music Generation (Vienna: Springer, 2009).

${ }^{27}$ A notable example in this context are popular "Adventure" games of the 1990s that employ a special programming language, iMUSE, to construct the complex net of musical nodes and to regulate their playback in reliance to the user's actions. For a description of the iMUSE system and the games in which it was used, see Karen Collins, Game Sound: An Introduction to the History, Theory, and Practice of Video Game Music and Sound Design (Cambridge, MA: MIT Press, 2008), 51-57. This network-based approach is commonly addressed in literature on music in video games as the game's and music's "non-linearity." Ibid., 142ff.

${ }^{28}$ For a discussion of the discourse on the unconscious, automatic, and rule-based creation of melodies into which the music machines of the nineteenth century were deeply embedded, see David Trippett, Wagner's Melodies: Aesthetics and Materialism in German Musical Identity (Cambridge: Cambridge University Press, 2013), 96-102.
}

in the wake of Jean Paul and E. T. A. Hoffman. ${ }^{29}$ At the same time, the mechanical musical machines have offered examples of technologies in which the creative potential of the user was radically removed from the process by relying on chance and randomization. In light of this, the emergence of computer-based works of academic composers during the twentieth and the twentyfirst centuries should not be seen exclusively as a result of the availability of the digital technologies. Rather, this appears also to be the outcome of a long discursive development, and a genealogy that started with the first paper-based musical machines. ${ }^{30}$

\section{Why QuADrilles?}

Aside from the historical models for the mathematical principles underlying the Melodist, we may wonder about the choice of genre: Why did Clinton choose quadrilles in particular for implementation? One response points simply to the commercial appeal of parlor entertainment. Quadrilles were a popular genre of group dancing in the nineteenth century. After their success in Napoleon's Paris they were imported into the culture of Georgian London in 1815, even as Europe was undergoing the process of restoring monarchies that had been temporarily displaced by Napoleon's empire. Often, quadrilles were adapted from other popular works. ${ }^{31}$ The names of the parts that make up the quadrille (such as Le Pantalon and L'Été) can thus be understood as subgenres in their own right: family types rather than stable, individual pieces

\footnotetext{
${ }^{29}$ See Trippett, Wagner's Melodies, $13 f f$.

${ }^{30}$ An overview of early and experimental programming environments for the creation of music is offered in Alan Fabian Eine Archäologie der Computermusik: Wissen über Musik und zum Computer im angehenden Informationszeitalter (Berlin: Kadmos, 2013). Examples of both historical and more recent compositional tools can be found in Michael Edwards, "Algorithmic Composition: Computational Thinking in Music," Communications of the ACM 54, no. 7 (2011): 58-67, https://doi.org/10.1145/1965724.1965742. Michael Nyman, Experimental Music: Cage and Beyond, 2nd edn. (Cambridge: Cambridge University Press, 1999| offers a discussion of related musical work by John Cage and other composers. For an example of the use of randomness in nonacademic experimental music, see Brian Eno: Oblique Music, ed. Sean Albiez and David Pattie (London: Bloomsbury Academic, 2016).

${ }^{31}$ See Andrew Lamb, "Quadrille," Grove Music Online, https://doi.org/10.1093/gmo/9781561592630.article.22622.
} 
of music. A comparison of quadrilles by different composers shows that they are connected primarily by their predictable, dance-orientated form and by broader musical features, and not by-for instance-a universally shared melody or harmonic gesture. ${ }^{32}$ Andrew Lamb has characterized such music as "made up of lively, rhythmic themes of rigid eight- or sixteen-bar lengths" and mentions the "plundering of all sorts of musical sources for themes for new dances and the musical distortions that often had to be made to satisfy the restricted musical form of the quadrille." ${ }^{\prime 33}$ It would seem the Melodist aims to cultivate exactly this characteristic and, to a certain extent, to mechanize the process of finding new musical material for use as accompaniment for dance. Its "directions for use" point explicitly to the problem of creating or adapting melodies that would fit the form of the dance, and advertise the method as a solution. ${ }^{34}$ Since quadrille melodies were borrowed from a wide range of sources anyway, the idea of a simple "machine" capable of endlessly producing them was suggestive in itself. Two aspects facilitated such thinking: on the one hand, the expectations for the artistic quality of such melodies was not high, as they were primarily seen as quasi-functional music that merely needs to accompany the dance figures while creating a certain standardized musical impression, ${ }^{35}$ on the other hand, the industrialization of production, transport and other areas of life prompted the development of experimental systems that tried also to mechanize cognitive processes such as calculation (exemplified in Babbage's proposed machines) or composition.

One prominent feature of quadrille dancing was the constant recombination of the eight

\footnotetext{
${ }^{32}$ See the Quadrilles pour la harpe by Prumier. Further examples for the genre-like character that broadly unites different quadrille pieces can be found in Johann Strauss Jr.'s Fledermaus-Quadrille or in the Rats Quadrilles by Jullien.

${ }^{33}$ Lamb, "Quadrille."

34"At Quadrille Parties, where Professional Performers are not engaged, an inconvenience frequently arises from want of Quadrille Music, the possession of this work will supply that deficiency." Quadrille Melodist, "General Explanation and Directions for Use."

${ }^{35}$ In a way, such quadrilles were as removed from the idea of the musical genius as the pieces that were played on the streets of Victorian London by organ grinders.
}

participants into changing groups. To avoid the monotony of repeating movements, and probably also to facilitate social contact, the four pairs of dancers were constantly switching partners and positions, thus already engaging in something like a combinatorial dance game. ${ }^{36}$ Therefore, seemingly, Clinton's method was not only following a line of development in music games that suggested the use of combinations, but also adhering to certain intrinsic qualities of the dance itself.

Embedded as it was in the discourse of ars combinatoria, the Quadrille Melodist often alluded to the world of mathematics, either explicitly ("By calculation it is ascertained that . ..") or gesturally, by providing exact numerical values ("462 Cards," "each rack is divided into 21 divisions" etc.). ${ }^{37}$ Overall, numbers formed a significant part of the discursive character in which the Melodist was presented to the public. As plate 2 shows, the high number of possible combinations was directly contrasted with the moderate (reduced) price of five shillings and sixpence, suggesting that the price pro quadrille must be negligibly small in this case. ${ }^{38}$

Given that the price of the system is presented so prominently, the question arises as to who the potential buyers and users were. Clearly, the method was aimed at a cultured public, presupposing a purchaser who was musically trained and who engaged in such activities as balls and social dancing. But did the potential customers have to be wealthy, or to belong to the upper classes? The price suggests that while the method was certainly too costly for the poorest inhabitants of Victorian London, it was comparable to the cost of large or sophisticated

\footnotetext{
${ }^{36}$ For example, a quadrille textbook published in 1822 offers a table of fifty-two different dancing figures, arranged in circles made up of card-like segments: Thomas Wilson, The Quadrille and Cotillion Panorama. 2d Ed., with the Addition of Nine Designs, to Illustrate the Performance of the Figures (London: R. \& E. Williamson, 1822). https:// www.loc.gov/resource/musdi.167.0/? $\mathrm{sp}=1$.

${ }^{37}$ Quadrille Melodist, "General Explanation and Directions for Use."

${ }^{38}$ Of course, such economic reasoning only works hypothetically, as no single user of the method could (or would want to) play all possible combinations. Yet, the psychology of selling the musical product via the supposedly endless possibilities for its use (as opposed to a limited, but real number of use scenarios) is an interesting point here.
} 


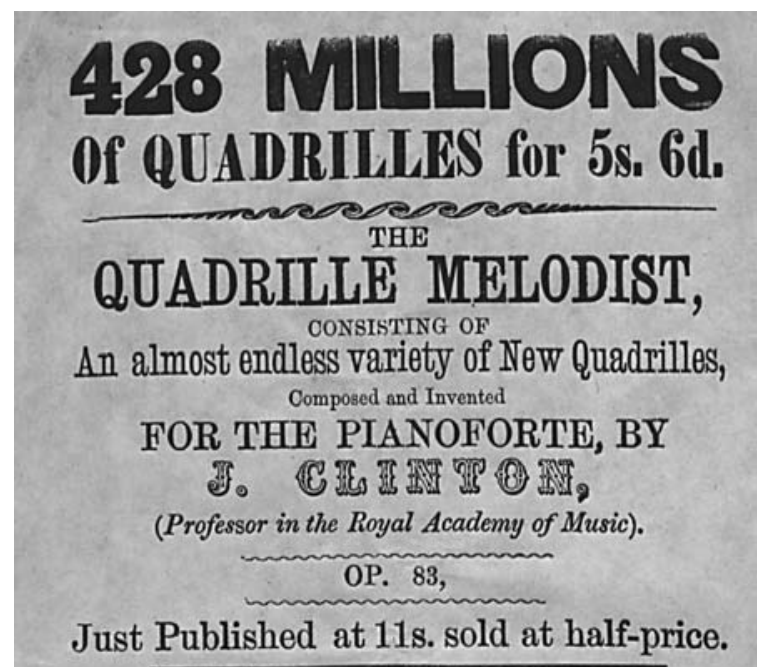

Plate 2: Advertisement for the Quadrille Melodist (detail). (C) British Library Board (Music Collections M.1.).

musical prints. ${ }^{39}$ As plate 3 shows, George Cruikshank satirized the social setting of quadrilles, in which bumbling bodies were prone to crash inelegantly into one another. It is a setting, moreover, in which the Quadrille Melodist might have been used: an upper-middle-class public (indicated in the caricature by the paintings on walls and a chandelier) engaging in a public but informal performance of quadrilles. ${ }^{40}$

\footnotetext{
${ }^{39}$ In the catalogue of Clinton's flute works (cited above) the Quadrille Melodist belongs to the group of the more expensive prints (its price is given there as fifteen shillings). When the Melodist was advertised in 1865 (sold at five shillings sixpence), the same page of the Musical Times offered a "Selection of school rounds" for four pennies and a "handsomely bound" "Church Chorale and HymnBook" for seven shillings sixpence. Musical Times and Singing Class Circular 11, no. 263 (1 January 1865): 447. http://www.jstor.org/stable/3351904. Note that the wording of the Quadrille Melodist advertisement has a more sensationalist tone than most of the other texts: "CAN IT BE TRUE? YES! Go and see for yourself. 428 Millions of Quadrilles, in one work, by J. CLINTON, late Professor in the Royal Academy of Music." The Musical Times and Singing Class Circular 12/265 (1 March 1865): 2. Charles Booth's Map Descriptive of London Poverty, 1898-9 lists a family with a weekly income of eighteen to twenty-one shillings as "poor." According to the same map, Clinton's own address, 14 Greek Street, is classified as "Fairly comfortable. Good ordinary earnings." https://booth.lse.ac.uk/ $\operatorname{map} / 18 /-0.1315 / 51.5143 / 100 / 0$.

${ }^{40}$ Compare George Cruikshank, "Natural Accidents in Practicing Quadrille Dancing," n.d., http://collections.vam. ac.uk/item/O579819.
}

It is no surprise, then, that the "directions for use" mention the "Musical Amateur" as the envisioned user of the system. Thus, from an economic point of view it appears that by creating aesthetic content through a semiautomatic process the dance's most expensive part, the hired professional piano player who would be able to create variations without the use of the system, is removed from the scene.

But what status does Clinton occupy, then, vis-à-vis the vacant position of the originator of the music? The issue of authorship is ambiguous in the Quadrille Melodist's presentation. On the one hand, the "directions for use" statement ends by cautioning that "the whole of the Melodies obtained from this work are Copyright; consequently they cannot be published in any form without the permission (in writing) of the Proprietors." This warning seems to imply that not only the cards themselves but each and every one of the melodies arising from their combination are already protected by copyright (even if the melodies themselves are not yet known or putatively extant). This raises an intricate legal question: would it be valid then (or now) to protect melodies that can be potentially created, melodies latent to the combinatorial system but which have not actually been created so far? More broadly, this situation touches upon the question of whether the results of work carried 


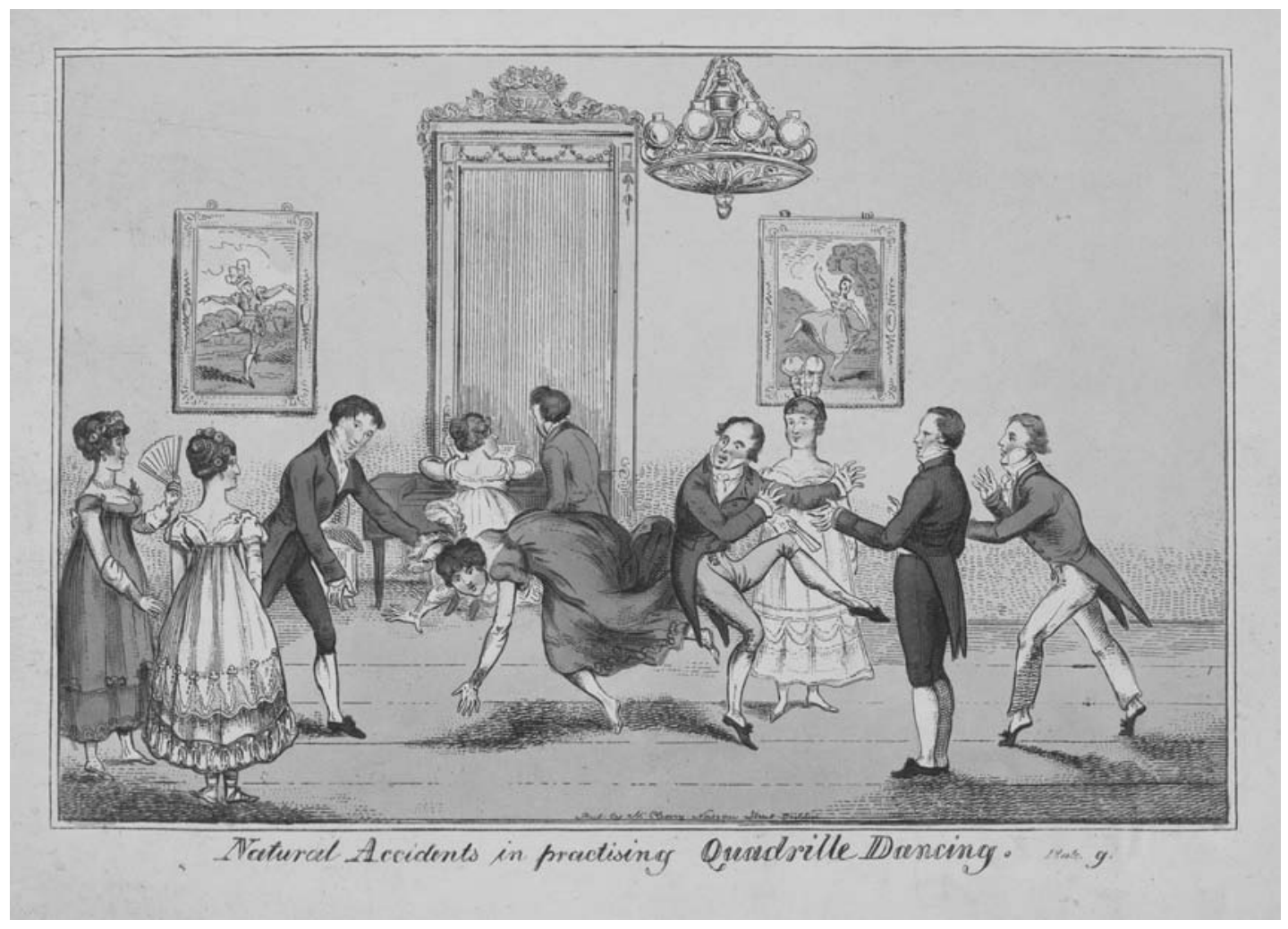

Plate 3: George Cruikshank's satire of Quadrille dancers: "Natural accidents in practicing Quadrille Dancing," ca. 1820. (C) Victoria and Albert Museum (E.503-1955).

out using a specific tool can be seen as belonging to the creator of the tool, to the tool itself, or to the person who used it. On the other hand, Clinton and the publisher limited the amount of personal information that identified Clinton as the author. Unlike the catalogue of Clinton's flute works, the Melodist does not give his address or invite the public to take lessons in music from him, most probably indicating that he died before the system was printed. It is telling in this regard that the year of publication is not given. ${ }^{41}$ Nevertheless, the machine-like qualities of the Melodist and its status as a system clearly connect to Clinton's experience as a designer and inventor of flutes. Like the complex sonic mechanism of a

\footnotetext{
${ }^{41}$ Since the Quadrille Melodist bears the opus number 83 its creation can be dated to a period that was decades earlier by the moment the system was advertised in 1865 , shortly after Clinton's death. (For comparison, Clinton's A Theoretical and Practical Essay on the Boehm Flute, op. 87, was published in 1843.)
}

modern flute, the Melodist pre-structures the possibilities of its musical use and thus helps the user achieve certain predefined results by imposing technical boundaries.

\section{Conclusion}

In this article, I considered the Quadrille Melodist from the point of view of its musical and physical structure, and probed the context of cultural developments in combinatorial aesthetics and the mechanization of music into which it was embedded. I showed that as a tool the Quadrille Melodist occupies a somewhat unstable position between the fully static medium of printed music and the fully operational calculator proposed by Babbage, roughly coeval with Clinton's Melodist. The issues discussed here raise a number of intriguing questions: Was the divide between the worlds of music and mathematics really that large in Victorian London? Or did the publisher 
consciously avoid the unimaginably large number of combinations because it would seem either daunting or simply implausible to potential buyers? ${ }^{42}$ On the one hand, if reaching a couple of hundred million combinations was the only goal for Clinton, he could have saved himself a lot of work by relying more thoroughly on the laws of combinatorics. With only three cards per stack he could already achieve a larger number of combinations than the 428 million he advertised. ${ }^{43}$ On the other hand, here one also needs to discriminate between questions of combinatorial enumeration and the perception of music. Given the tendency of the listener to hear larger phrase structures rather than individual elements, with only three cards per stack a sense of monotony and repetition could inevitably become manifest too readily. Furthermore, the other uses proposed for the Melodist (such as sight-reading and composition training) would be impeded by having too few cards.

At the same time, the assumption that original or new music is desirable for a quadrille session is debatable. ${ }^{44}$ Wouldn't the constant variation run the risk of confusing the dancers? And wouldn't every performance be executed differently, even without changing the musical notes? In spite of what Elizabeth Margulis has called music's "stubborn repeatability," it remains impossible, after all, for a human player to repeat exactly every nuance of a musical performance's tempo, touch, phrasing, dynamics, and articulation. ${ }^{45}$

During the last decade, theoretical developments have reignited discussions of the role of technology in the production of music and

\footnotetext{
${ }^{42}$ Combinatorics was a popular field in non-professional and recreational mathematics at the time of the Melodist's printing. Combinatorial problems of a much higher order of complexity were published in journals for amateur mathematicians such as the Lady's and Gentleman's Diary. See Robin Wilson, "Combinatorics: A Very Victorian Recreation," in Mathematics in Victorian Britain, ed. Raymond Flood, Adrian Rice, and Robin Wilson (Oxford: Oxford University Press, 2011), 377-95.

${ }^{43}$ With three cards in each of the twenty-one stacks, there would have been 3 to the power of 21 , or $10,460,353,203$ different possibilities.

${ }^{44}$ Certainly, originality was not the central criterion for judging quadrille accompaniment.

${ }^{45}$ Elizabeth Margulis, On Repeat: How Music Plays the Mind (New York: Oxford University Press, 2014), 4.
}

their deep reciprocity. In this context, a musicologically informed analysis of a paper-based, machine-like technology like the Melodist can help us understand the cultural shifts that relate to the technological changes in the previous centuries. At the same time, the mathematical history of combinatorics as a discipline can also be enriched by drawing parallels between the mathematical discourse and the early examples of ars combinatoria broached above. In the end, the Quadrille Melodist shows that functioning music-generating systems were not always, and do not have to be, as complex as the setups that have been used by composers in the digital age. Nor do they depend on the preexistence of the computer as a technology.

\begin{abstract}
.
Quadrilles were a popular genre of group dancing in the nineteenth century. Existing melodies were normally used to accompany the dancing sessions, but the monotony of their repetition and the cost of a professional piano player capable of improvising were an issue. Thus, the idea of a "machine" that would be able to endlessly produce quadrille music at no cost was suggesting itself. The Quadrille Melodist, a paper-based system for the generation of piano pieces, was published in nineteenth-century Victorian London by John Clinton, a "professor in the Royal Academy of Music." Already in 1650, Athanasius Kircher proposed in his Musurgia Universalis a device consisting of stripes with short snippets of music that could be used to create combinatorial pieces and variations. By the beginning of the nineteenth century, a whole genre of quasi-algorithmic compositions was emerging, spurred by the popularity of such works as the Musikalisches Würfelspiel, a piece attributed to Mozart. In this article, I analyze the Quadrille Melodist against the background of the history of combinatorial music. I contrast its unique features with other predigital, as well as later digital, music systems and discuss its design with respect to the phenomenon of predictability in dance music. Additionally, I discuss reasons for the circumstance that the historically advertised number of possible quadrilles, 428 million, is much smaller than the real number of combinations. Keywords: John Clinton, quadrille, musical dice games, predictability, ars combinatoria
\end{abstract}

